\title{
Effects of Light and Dark Incubation on the Lipid and Fatty Acid Composition of Marine Cyanobacteria
}

\author{
By R. H. AL-HASAN, ${ }^{*}$ A. M. Ali And S. S. RADWAN \\ Department of Botany and Microbiology, Faculty of Science, Kuwait University, PO Box 5969, \\ Safat 13060, Kuwait
}

(Received 26 September 1988; accepted 1 December 1988)

\begin{abstract}
The effect of light and dark incubation on the ultrastructure, pigments and lipids of five marine cyanobacteria was studied. All light-grown cyanobacteria contained in their lipid extracts the four major lipid classes characteristic of chloroplasts, namely monogalactosyldiacylglycerols, digalactosyldiacylglycerols, sulphoquinovosyldiacylglycerols, and phosphatidyl glycerols. However, the fatty acid patterns of the cyanobacterial total lipids and individual lipid classes were different from those of chloroplasts, and responded differently to dark incubation. In two cyanobacteria the fatty acid patterns of total lipids from light- and dark-incubated cultures were similar, but in the other three, dark incubation was associated with increased levels of oleic acid in the total lipids and individual lipid classes. The decrease of linolenic acid known to occur in lipids from photosynthetic eukaryotes in response to dark incubation was recorded only in Spirulina subsalsa. However, linolenic acid was not esterified in monogalactosyldiacylglycerols, as it is in chloroplasts. We also found the class of alcohol glycosides in three non-heterocystous cyanobacteria.
\end{abstract}

\section{INTRODUCTION}

Results of many studies have repeatedly confirmed that the major lipid classes in chloroplasts and cyanobacteria are quite similar (for a review see Quinn \& Williams, 1983). However, this similarity does not involve the constituent fatty acids of the lipids. Lipids from photosynthetic eukaryotes contain particularly high concentrations of linolenic acid (Quinn \& Williams, 1983). On the other hand cyanobacteria are unique among the oxygenic phototrophs in lacking polyenoic fatty acids in their lipids (Holton et al., 1964; Parker et al., 1967). Acyl moieties in cyanobacterial lipids usually consist of saturated and monoenoic $\mathrm{C}_{16}$ and $\mathrm{C}_{18}$ fatty acids (Holton et al., 1968; Quinn \& Williams, 1983; Sallal et al., 1987). A few cyanobacteria, however, synthesize linolenic acid (Parker et al., 1967; Nichols \& Wood, 1968a; Sato \& Murata, 1980, 1982), but the distribution of this trienoic fatty acid among the various lipid classes has not yet been extensively studied.

Chloroplasts, irrespective of their origin, exhibit reproducible responses to illumination in their fine structure, composition of their lipid classes and fatty acid patterns of their lipids. Parallel responses in cyanobacteria have not been systematically studied, and the major objective of the present work was to make this information available.

\section{METHODS}

Organisms and growth. Five marine cyanobacteria identified as Anabaena constricta (strain KCCA/C100), Phormidium corium (KCCA/C200), Phormidium jenkelianum (KCCA/C210), Spirulina subsalsa (KCCA/C 300) and Synechocystis sp. (KCCA/C400) were isolated from a salt marsh in the Al-K hiran area, south of Kuwait. Water, mud and salt-crust samples were diluted and inoculated into medium MN (Waterbury \& Stanier, 1978). After 2 weeks the cultures were microscopically examined for cyanobacteria. Individual filaments were picked up by micropipettes and plated on medium MN solidified with $1 \%(w / v)$ agar. The cyanobacteria were subcultured four 
successive times on the same medium, incubating the cultures each time under continuous illumination (1500 lx) at a temperature of $38^{\circ} \mathrm{C}$ to control contaminating diatoms and green algae (Allen \& Stanier, 1968). Cyanobacteria free from diatoms and green algae were then passed four successive times in liquid medium MN supplemented with $150 \mathrm{U}$ benzylpenicillin $\mathrm{ml}^{-1}, 100 \mathrm{U}$ chloramphenicol ml-1 and $1000 \mathrm{U}^{-1}$ streptomycin sulphate $\mathrm{ml}^{-1}$ in an attempt to differentially inhibit growth of contaminating heterotrophic bacteria. Cyanobacterial cultures were considered axenic when they did not reveal any bacterial growth after $7 \mathrm{~d}$ incubation at $30^{\circ} \mathrm{C}$ on peptone/ sea water agar of the composition $\left(1^{-1}\right): 5 \mathrm{~g}$ bacto-peptone, $0.1 \mathrm{~g}$ ferric phosphate, $10 \mathrm{~g}$ agar (dissolved in $75 \%, \mathrm{v} / \mathrm{v}$, sea water) pH 6.8. The organisms were identified by consulting Desikachary (1959) and Rippka et al. (1979). A. constricta does not produce heterocysts and could be identified as Pseudanabaena constricta according to Lauterborn (1915).

Growth measurement and pigment analysis. Cyanobacteria grown under continuous illumination for $7 \mathrm{~d}$ and then incubated for another $7 \mathrm{~d}$ in the dark, and cultures maintained under continuous illumination throughout the $14 \mathrm{~d}$ period, were studied. The organisms were grown at $30^{\circ} \mathrm{C}$ in medium $\mathrm{MN}$ in 10-litre aspirators equipped with magnetic stirrers and sparged with sterile air, $30 \mathrm{ml} \mathrm{min}^{-1}$. Light $(3000 \mathrm{~lx}$ at the surfaces of the vessels) was provided by cool white fluorescent tubes. Culture samples $(5 \mathrm{ml})$ were withdrawn daily, and after grinding the cyanobacteria mildly in a tissue grinder (Wheatan Scientific, Millville, USA) for 3 min, the percentage transmission was read at $678 \mathrm{~nm}$ using a spectrophotometer (Bausch \& Lomb Spectronic 21). Pigments were extracted with $90 \%(\mathrm{v} / \mathrm{v})$ acetone in water (Hansmann, 1973) and chlorophyll $a$ and carotenoid concentrations determined using the equations of Parsons \& Strickland (1965) with a Beckman model 25 spectrophotometer.

Growth in a nitrogen-free medium was examined by inoculating cyanobacteria into a medium of the following composition : $5 \mathrm{~mm}-\mathrm{MgSO}_{4}, 0.3 \mathrm{mM}-\mathrm{CaCl}_{2}, 0.4 \mathrm{mM}-\mathrm{KH}_{2} \mathrm{PO}_{4}, 1.5 \mu \mathrm{M}-\mathrm{FeCl}_{3}, 0.6 \mu \mathrm{M}-\mathrm{CuSO}_{4}, 1 \mu \mathrm{M}-\mathrm{ZnSO}_{4}, 0.6 \mu \mathrm{M}-$ $\mathrm{CoCl}_{2}, 0.5 \mu \mathrm{M}-\mathrm{NaMoO}_{4}, 3.0 \%(\mathrm{w} / \mathrm{v}) \mathrm{NaCl} ; \mathrm{pH}$. Air, made free of nitrogen oxides and ammonia by passing it successively through $\mathrm{NaOH}, \mathrm{H}_{2} \mathrm{SO}_{4}$ and distilled water, was bubbled into the cultures. All five cyanobacteria were able to grow in this medium when nitrate $\left(5 \mathrm{~mm}-\mathrm{KNO}_{3}\right)$ was present.

Electron microscopy. Cyanobacterial filaments were taken from actively growing cultures and fixed with $3 \%$ (v/v) glutaraldehyde in cacodylate buffer, $\mathrm{pH} 7.5$, for $90 \mathrm{~min}$ at room temperature and embedded in $2 \%$ agar. Each agar block was divided into small cubes which were fixed with buffered $1 \%(\mathrm{w} / \mathrm{v}) \mathrm{OsO}_{4}$ for $90 \mathrm{~min}$ at $40^{\circ} \mathrm{C}$. The cubes were dehydrated by passing them through an ascending series of acetone and were then embedded in Epon. The cured resin blocks were sectioned using an LKB ultramicrotome equipped with a glass knife. The ultrathin sections were stained by uranyl acetate. Electron micrographs were recorded with a Jeol electron microscope.

Lipid extraction and analysis. As far as feasible, all steps were done in an atmosphere of oxygen-free nitrogen. Total lipids were extracted with boiling 2-propanol/chloroform $(1: 2, \mathrm{v} / \mathrm{v})$ to deactivate lipases (Kates, 1972; Radwan, 1984) and purified following established procedures (Folch et al., 1957). The composition of lipid classes was studied by thin-layer chromatography (TLC) using silica gel plates. Non-polar compounds were fractionated using hexane/diethyl ether/acetic acid (90:10:1, by vol.) (Mangold \& Malins, 1960). Ionic and other polar lipids were resolved by two-dimensional TLC using chloroform/methanol/7 M-ammonium hydroxide $(65: 25: 4$, by vol.) in the first direction and chloroform/methanol/acetic acid/water $(170: 25: 25: 2$, by vol.) in the second direction (Nichols, 1964). The lipid fractions were detected with iodine vapour or by charring after spraying the plates with $50 \%(\mathrm{v} / \mathrm{v}) \mathrm{H}_{2} \mathrm{SO}_{4}$. Individual lipid classes were identified by comparing their chromatographic behaviour with that of authentic samples and by using specific spray reagents (Dittmer \& Lester, 1964; Siakotos \& Rouser, 1965; Vioque, 1984). To confirm the identity of a glycolipid tentatively identified as alcohol glycoside, samples of the pure compound were separated by preparative TLC and eluted from the adsorbent with chloroform/diethyl ether/ethanol (1:1:1, by vol.) (Kates, 1972) and subjected to acid hydrolysis (Gaver \& Sweeley, 1965). Hydrolysis products soluble in hexane were analysed by TLC and sugar moieties remaining in the aqueous phase were identified by paper chromatography (Menzies \& Seakins, 1976). Samples of total lipids and of individual lipid classes, separated by preparative TLC (Radwan, 1978), were subjected to methanolysis with $2 \% \mathrm{H}_{2} \mathrm{SO}_{4}$ in absolute methanol at $90^{\circ} \mathrm{C}$ for $90 \mathrm{~min}$ (Chalvardjian, 1964). The resulting methyl esters of fatty acids were recovered with hexane, purified by preparative TLC and analysed by GLC using a Pye-Unicam 204 gas chromatograph equipped with a glass column $(1.83 \mathrm{~m} \times 4 \mathrm{~mm}$ i.d.) packed with $15 \%(\mathrm{w} / \mathrm{w})$ DEGS on Anakrom D (100-200 mesh) and operated isothermally at $170^{\circ} \mathrm{C}$ with nitrogen as the carrier gas. Individual fatty acids were identified by comparing their retention times with those of standard samples as well as by using the 'equivalent chain length' method of Miwa et al. (1960).

\section{RESULTS}

\section{Growth and pigments}

The five axenic cultures of marine cyanobacteria grew well in medium $\mathrm{MN}$ under the conditions described above. Only $A$. constricta grew, although very weakly, in the nitrogen-free medium, indicating its poor ability to fix atmospheric nitrogen under aerobic conditions. 
Table 1. Effect of light on the lipid and pigment contents of marine cyanobacteria

Values are the means of three determinations.

\begin{tabular}{|c|c|c|c|c|c|c|c|c|}
\hline \multirow[b]{2}{*}{ Cyanobacterium } & \multicolumn{2}{|c|}{$\begin{array}{l}\text { Total lipids } \\
\text { (\% of dry wt) }\end{array}$} & \multicolumn{2}{|c|}{$\begin{array}{l}\text { Chlorophyll } \\
\left(\mathrm{mg} \mathrm{1}^{-1}\right)\end{array}$} & \multicolumn{2}{|c|}{$\begin{array}{l}\text { Carotene } \\
\left(\mathrm{mg} \mathrm{1}^{-1}\right)\end{array}$} & \multicolumn{2}{|c|}{$\begin{array}{l}\text { Carotene to } \\
\text { chlorophyll ratio }\end{array}$} \\
\hline & Light & Dark & Light & Dark & Light & Dark & Light & Dark \\
\hline $\begin{array}{l}\text { A. constricta } \\
\text { P. corium } \\
\text { P. jenkelianum } \\
\text { Spirulina subsalsa } \\
\text { Synechocystis sp. }\end{array}$ & $\begin{array}{l}8.2 \\
5 \cdot 6 \\
4.5 \\
6.5 \\
1 \cdot 2\end{array}$ & $\begin{array}{l}1.6 \\
4 \cdot 2 \\
1.4 \\
7 \cdot 8 \\
0.9\end{array}$ & $\begin{array}{l}29 \\
11 \\
11 \\
10 \\
22\end{array}$ & $\begin{array}{r}13 \\
3 \\
9 \\
6 \\
18\end{array}$ & $\begin{array}{l}38 \\
18 \\
36 \\
41 \\
37\end{array}$ & $\begin{array}{l}22 \\
13 \\
34 \\
31 \\
15\end{array}$ & $\begin{array}{l}1 \cdot 3 \\
1.6 \\
3 \cdot 3 \\
4 \cdot 1 \\
1 \cdot 7\end{array}$ & $\begin{array}{l}1 \cdot 7 \\
4 \cdot 3 \\
3 \cdot 8 \\
5 \cdot 2 \\
0 \cdot 8\end{array}$ \\
\hline
\end{tabular}

Growth in medium MN was exponential for $7 \mathrm{~d}$, with population doubling times ranging between about $21 \mathrm{~h}$ for Synechocystis sp. and $13 \mathrm{~h}$ for Spirulina subsalsa. Light-incubated cultures apparently reached stationary phase, as they did not grow further after another $7 \mathrm{~d}$ period under continuous illumination or when transferred to the dark. However, in all cultures the chlorophyll $a$ and carotene contents decreased in response to dark incubation (Table 1). The carotene to chlorophyll $a$ ratio increased in the dark in $A$. constricta, $P$. corium and Spirulina subsalsa, remained unchanged in $P$. jenkelianum and decreased in Synechocystis sp. (Table 1).

Dark incubation was associated with morphological and visible colour changes. For example, cultures of $A$. constricta were deep blue-green in the light but yellowish green in the dark. The mean number of cells per trichome of $A$. constricta in the light was $80 \pm 7$ (mean $\pm \mathrm{SD}, n=100$ ) and in the dark only $8 \pm 2$. Cells in the light-incubated trichomes were more or less cylindrical and separated by clear constrictions, but in the dark they were spherical and commonly thicker (probably akinetes), giving the trichome a beaded appearance.

\section{Ultrastructure}

Electron micrographs showed that the photosynthetic lamellae of light-incubated $A$. constricta were compact and regularly appressed to each other (Fig. 1). In contrast, photosynthetic lamellae of dark-incubated cultures were much less compact and less regularly appressed to each other, and the intrathylakoidal spaces were dilated (Fig. 1). Light-incubated cells, particularly of Spirulina subsalsa, contained arrays of phycobilisomes in the interthylakoidal space, whereas dark-incubated cells contained few phycobilisomes.

\section{Lipid composition}

The total lipid content of $A$. constricta and $P$. jenkelianum decreased in the dark, whereas that of the three other cyanobacteria was relatively little affected (Table 1). The major lipid classes in extracts from light-incubated cyanobacteria (Fig. 2) were monogalactosyldiacylglycerols, digalactosyldiacylglycerols, sulphoquinovosyldiacylglycerols and phosphatidyl glycerols. Substantial proportions of triacylglycerols and fatty acids in addition to traces of several unidentified polar compounds were also present. Sterols and complex lipids containing sterols were not detected. Lipid extracts from $P$. corium and Synechocystis sp. and, to a lesser extent $A$. constricta, contained major proportions of alcohol glycosides, a class which was not detected in extracts of the two other cyanobacteria (Fig. 3). Acid hydrolysis of this fraction from P. corium, isolated by preparative TLC from total lipids, showed that the sugar moiety consisted of glucose bound to long-chain alcohols. These long-chain alcohols were identified by their thin-layer chromatographic behaviour and by their IR absorption band at $3500 \mathrm{~cm}^{-1}$, characteristic of the $(\mathrm{OH})$ group.

Dark incubation resulted in a decrease in the concentration of monogalactosyldiacylglycerols, digalactosyldiacylglycerols and sulphoquinovosyldiacylglycerols in extracts from $\boldsymbol{P}$. corium and $A$. constricta but not from $P$. jenkelianum, Spirulina subsalsa and Synechocystis sp. (Fig. 3). Alcohol glycosides in lipid extracts from $P$. corium, Synechocystis sp. and $A$. constricta decreased in the dark. The fatty acid patterns of total lipids from marine cyanobacteria are summarized in 

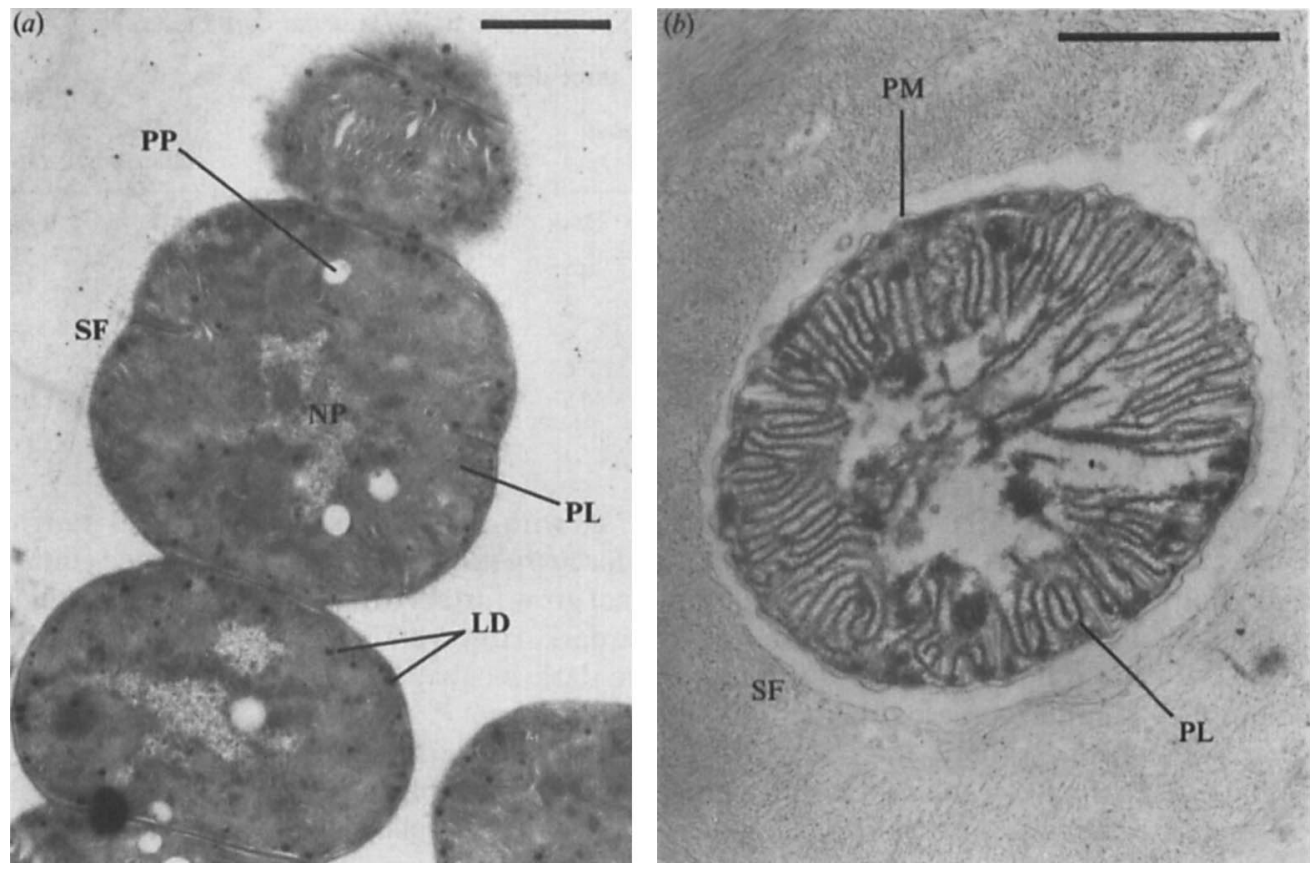

Fig. 1. Electron micrographs of $(a)$ light- and $(b)$ dark-incubated cells of $A$. constricta. PL, photosynthetic lamellae; SF, sheath fibre; PM, plasma membrane; NP, nucleoplasmic region; LD, lipid droplets; PP, polyphosphate. Bars, $1 \mu \mathrm{m}$.

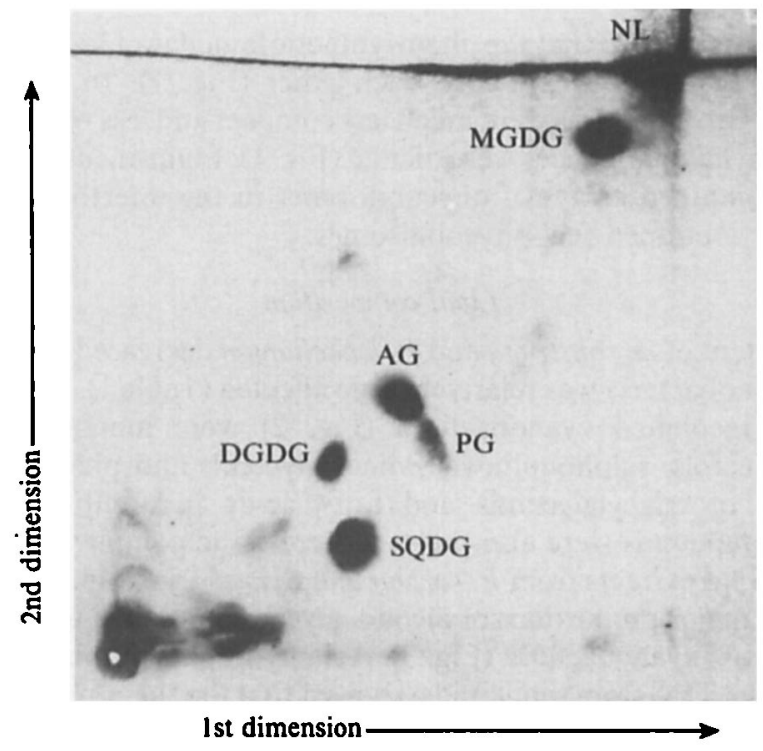

Fig. 2. Typical two-dimensional thin-layer chromatogram showing the composition of lipid classes of $P$. corium incubated under continuous illumination. TLC was done using silica gel $G$ plates and the following solvent systems: chloroform/methanol/7 M-ammonium hydroxide $(65: 25: 4$, by vol.) in the first direction, and chloroform/methanol/acetic acid/water $(170: 25: 25: 2$, by vol.) in the second direction. The lipid fractions were visualized by charring after spraying with $50 \% \mathrm{H}_{2} \mathrm{SO}_{4}$. O, origin; NL, neutral lipids + pigments; MGDG, monogalactosyldiacylglycerols; PG, phosphatidylglycerols; AG, alcohol glycosides, DGDG, digalactosyldiacylglycerols; SQDG, sulphoquinovosyldiacylglycerols. Several unidentified polar lipids are present in small amounts. 


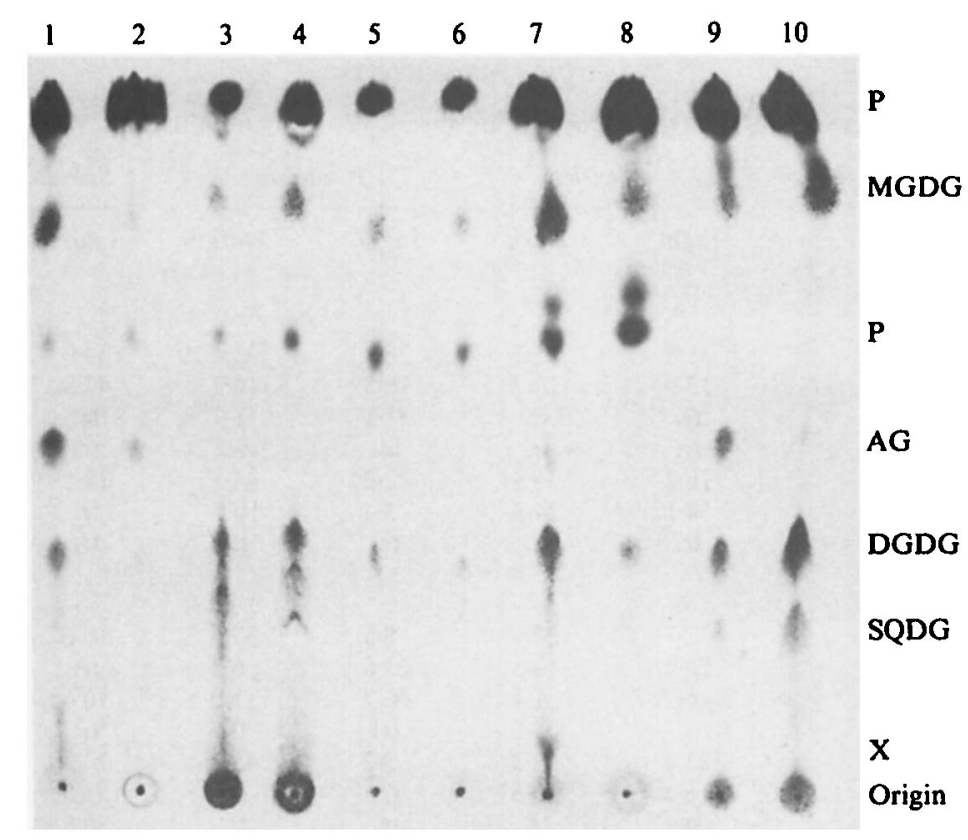

Fig. 3. Typical TLC plate showing the effect of light on the major glycolipids of cyanobacteria. TLC was done using silica gel $G$ and chloroform/methanol/acetic acid/water $(85: 12: 12: 1$, by vol.) as solvent. The glycolipid fractions were visualized by spraying with $\alpha$-naphthol and $\mathrm{H}_{2} \mathrm{SO}_{4}$ and heating at $100^{\circ} \mathrm{C}$. MGDG, monogalactosyldiacylglycerols; P, pigments; AG, alcohol glycosides; DGDG, digalactosyldiacylglycerols; SQDG, sulphoquinovosyldiacylglycerols; $\mathrm{X}$, unknown glycolipid. $P$. corium light (lane 1), dark (lane 2); . jenkelianum light (lane 3), dark (lane 4); Spirulina subsalsa light (lane 5), dark (lane 6); A. constricta light (lane 7) dark (lane 8); Synechocystis sp. light (lane 9), dark (lane 10).

Table 2. Effect of light on the constituent fatty acids of total lipids from marine cyanobacteria Values are expressed as percentages and are means of two determinations. tr., Trace.

\begin{tabular}{|c|c|c|c|c|c|c|c|c|c|c|}
\hline \multirow{2}{*}{$\begin{array}{l}\text { Fatty } \\
\text { acid }\end{array}$} & \multicolumn{2}{|c|}{ A. constricta } & \multicolumn{2}{|c|}{ P. corium } & \multicolumn{2}{|c|}{ P. jenkelianum } & \multicolumn{2}{|c|}{ Spirulina subsalsa } & \multicolumn{2}{|c|}{ Synechocystis sp. } \\
\hline & Light & Dark & Light & $\overbrace{\text { Dark }}$ & Light & Dark & Light & Dark & Light & Dark \\
\hline $16: 0$ & $32 \cdot 1$ & $26 \cdot 0$ & $34 \cdot 8$ & $38 \cdot 0$ & $28 \cdot 6$ & $28 \cdot 5$ & $15 \cdot 0$ & $21 \cdot 8$ & $23 \cdot 8$ & $23 \cdot 5$ \\
\hline $16: 1$ & $14 \cdot 1$ & $11 \cdot 3$ & $13 \cdot 2$ & $10 \cdot 4$ & 18.6 & $18 \cdot 4$ & 16.7 & $20 \cdot 4$ & $4 \cdot 8$ & $4 \cdot 2$ \\
\hline $16: 2$ & $1 \cdot 3$ & 1.0 & $14 \cdot 2$ & $2 \cdot 0$ & tr. & tr. & $19 \cdot 2$ & $5 \cdot 6$ & $3 \cdot 0$ & 5.0 \\
\hline $18: 0$ & 1.8 & $5 \cdot 2$ & tr. & tr. & tr. & tr. & tr. & tr. & 0.9 & 0.9 \\
\hline $18: 1$ & $17 \cdot 6$ & 37.7 & $30 \cdot 4$ & $39 \cdot 6$ & 35.7 & 35.9 & 27.6 & $44 \cdot 4$ & $18 \cdot 8$ & $17 \cdot 1$ \\
\hline $18: 2$ & 29.3 & $18 \cdot 2$ & $7 \cdot 4$ & $10 \cdot 0$ & 11.4 & $11 \cdot 5$ & 11.4 & $7 \cdot 8$ & 23.4 & 26.9 \\
\hline $18 \cdot 3$ & 3.8 & 0.5 & tr & tr. & 5.7 & 5.7 & $10 \cdot 1$ & tr. & $25 \cdot 2$ & $22 \cdot 1$ \\
\hline
\end{tabular}

Table 2. Saturated and monoenoic $\mathrm{C}_{16}$ fatty acids and monoenoic and dienoic $\mathrm{C}_{18}$ fatty acids predominated. Considerable proportions of $\mathrm{C}_{16: 2}$ were present in lipids from $P$. corium and Spirulina subsalsa and of $\mathrm{C}_{18: 3}$ in lipids from Synechocystis sp. and Spirulina subsalsa. In $P$. jenkelianum and Synechocystis sp. the fatty acid patterns of total lipids wee similar in the light and dark. In lipids from the other three cyanobacteria, dark incubation was associated with increases in the concentration of oleic acid $\left(\mathrm{C}_{18: 1}\right)$. Simultaneously the levels of $\mathrm{C}_{16: 2}$ in lipids from $P$. corium and Spirulina subsalsa and of $\mathrm{C}_{18: 3}$ in lipids from Spirulina subsalsa decreased.

In the major lipid classes of $A$. constricta, $P$. corium and Spirulina subsalsa, oleic acid $\left(\mathrm{C}_{18: 1}\right)$ increased considerably in the dark (Table 3 ). In these three organisms the highest concentration 
Table 3. Effect of light on the patterns of constituent fatty acids of major lipid classes from marine cyanobacteria

Values are expressed as percentages and are means of two determinations. tr., Trace.

\begin{tabular}{|c|c|c|c|c|c|c|}
\hline \multirow{2}{*}{$\begin{array}{c}\text { Fatty } \\
\text { acid }\end{array}$} & \multicolumn{2}{|c|}{ A. constricta } & \multicolumn{2}{|c|}{ P. corium } & \multicolumn{2}{|c|}{ Spirulina subsalsa } \\
\hline & Light & Dark & Light & Dark & Light & Dark \\
\hline \multicolumn{7}{|c|}{$\begin{array}{c}\text { Monogalactosyl- } \\
\text { diacylglycerols }\end{array}$} \\
\hline $16: 0$ & $31 \cdot 8$ & $25 \cdot 3$ & $26 \cdot 8$ & $33 \cdot 4$ & $34 \cdot 0$ & $23 \cdot 7$ \\
\hline $16: 1$ & $15 \cdot 9$ & $13 \cdot 7$ & $16 \cdot 5$ & $10 \cdot 7$ & $47 \cdot 8$ & $22 \cdot 2$ \\
\hline $16: 2$ & tr. & tr. & $31 \cdot 1$ & $11 \cdot 7$ & tr. & tr. \\
\hline $18: 0$ & tr. & tr. & tr. & tr. & tr. & tr. \\
\hline $18: 1$ & $18 \cdot 2$ & $36 \cdot 4$ & $22 \cdot 0$ & $44 \cdot 1$ & $18 \cdot 1$ & $25 \cdot 2$ \\
\hline $18: 2$ & $34 \cdot 1$ & $24 \cdot 3$ & $3 \cdot 4$ & tr. & tr. & $28 \cdot 9$ \\
\hline $18: 3$ & tr. & tr. & tr. & tr. & tr. & $\operatorname{tr}$ \\
\hline \multicolumn{7}{|c|}{$\begin{array}{l}\text { Digalactosyl- } \\
\text { diacylglycerols }\end{array}$} \\
\hline $16: 0$ & $32 \cdot 7$ & $27 \cdot 1$ & $8 \cdot 5$ & $37 \cdot 6$ & $10 \cdot 6$ & 33.9 \\
\hline $16: 1$ & $20 \cdot 8$ & $13 \cdot 3$ & $21 \cdot 6$ & $6 \cdot 3$ & tr. & $32 \cdot 7$ \\
\hline $16: 2$ & 6.7 & 1.4 & $66 \cdot 7$ & $11 \cdot 0$ & $10 \cdot 6$ & tr. \\
\hline $18: 0$ & tr. & $4 \cdot 2$ & tr. & tr. & tr. & 4.9 \\
\hline $18: 1$ & $23 \cdot 4$ & $33 \cdot 3$ & $3 \cdot 2$ & $45 \cdot 1$ & $20 \cdot 9$ & $25 \cdot 7$ \\
\hline $18: 2$ & $16 \cdot 5$ & $20 \cdot 6$ & tr. & tr. & $21 \cdot 3$ & tr. \\
\hline $18: 3$ & tr. & tr. & tr. & tr. & $36 \cdot 6$ & 2.7 \\
\hline \multicolumn{7}{|c|}{$\begin{array}{l}\text { Sulphoquinovosyl- } \\
\text { diacylglycerols }\end{array}$} \\
\hline $16: 0$ & 31.0 & $18 \cdot 3$ & $49 \cdot 3$ & $50 \cdot 1$ & 10.0 & tr. \\
\hline $16: 1$ & $23 \cdot 1$ & $2 \cdot 1$ & 9.9 & $9 \cdot 7$ & tr. & tr. \\
\hline $16: 2$ & tr. & tr. & 19.7 & 5.8 & $46 \cdot 8$ & tr. \\
\hline $18: 0$ & tr. & $4 \cdot 1$ & tr. & tr. & tr. & tr. \\
\hline $18: 1$ & 8.7 & 59.6 & $21 \cdot 1$ & $39 \cdot 2$ & 15.8 & $80 \cdot 3$ \\
\hline $18: 2$ & $37 \cdot 2$ & 15.9 & tr. & tr. & $14 \cdot 5$ & $19 \cdot 7$ \\
\hline $18: 3$ & tr. & tr. & tr. & tr. & $13 \cdot 0$ & tr. \\
\hline \multicolumn{7}{|c|}{$\begin{array}{l}\text { Phosphatidyl- } \\
\text { glycerols }\end{array}$} \\
\hline $16: 0$ & $50 \cdot 5$ & 31.9 & $64 \cdot 8$ & $45 \cdot 3$ & $60 \cdot 1$ & $45 \cdot 3$ \\
\hline $16: 1$ & 3.8 & 2.9 & $11 \cdot 1$ & $9 \cdot 6$ & 6.9 & $11 \cdot 6$ \\
\hline $16: 2$ & tr. & tr. & tr. & tr. & tr. & tr. \\
\hline $18: 0$ & tr. & 4.4 & tr. & tr. & tr. & tr. \\
\hline $18: 1$ & $26 \cdot 1$ & 56.4 & $23 \cdot 8$ & $45 \cdot 1$ & 33.0 & $31 \cdot 3$ \\
\hline $18: 2$ & 19.6 & $4 \cdot 4$ & tr. & tr. & tr. & $5 \cdot 2$ \\
\hline $18: 3$ & tr. & tr. & tr. & tr. & tr. & $6 \cdot 4$ \\
\hline
\end{tabular}

of palmitic acid $\left(\mathrm{C}_{16: 0}\right)$ was detected in phosphatidylglycerols and the concentration of this fatty acid decreased in the dark. Most of the $\mathrm{C}_{16: 1}$ was esterified in monogalactosyldiacylglycerols and digalactosyldiacylglycerols of the three cyanobacteria, although relatively high concentrations of this fatty acid were also present in sulphoquinovosyldiacylglycerols of $A$. constricta and to a lesser extent of $P$. corium. Most of the $\mathrm{C}_{16: 2}$ was esterified in digalactosyldiacylglycerols of the three organisms; in $\boldsymbol{P}$. corium it was also found in monogalactosyldiacylglycerols, and in Spirulina subsalsa in sulphoquinovosyldiacylglycerols. Linolenic acid $\left(C_{18: 3}\right)$ occurred in Spirulina subsalsa only, in digalactosyldiacylglycerols and sulphoquinovosyldiacylglycerols, and its concentration in these glycolipids decreased in the dark.

\section{DISCUSSION}

The five marine cyanobacteria studied did not respond to dark incubation in the same way. Response variations involved the pigmentation, the total lipid contents and the fatty acid patterns of total lipids and of individual lipid classes. These variations reflect the heterogeneity of cyanobacteria as a taxonomic group. 
All the cyanobacteria studied showed an ultrastructural change in response to the dark incubation similar to that described for other cyanobacteria (Fogg et al., 1973; Lang \& Whitton, 1973; Stulp, 1982) and chloroplasts (Luning \& Schmitz, 1988). In this context it should be noted that most of the cyanobacterial lipids occur in the photosynthetic membranes with minor proportions in the plasma membranes. None of the five cyanobacteria showed responses similar to those known for chloroplasts, especially as far as lipids are concerned. The total lipid content of chloroplasts and photosynthetic eukaryotes decreases in the dark (Radwan \& Mangold, 1980 ), but in our study this was true for $A$. constricta and P. jenkelianum only. Although, confirming earlier reports (Quinn \& Williams, 1983; Sallal et al., 1987), the composition of lipid classes in the five cyanobacteria incubated in the light was similar to that of illuminated chloroplasts, incubating the cyanobacteria in the dark brought about important differences. The major lipid classes of chloroplasts are known to decrease in the dark (Quinn \& Williams, 1983). This was found true for $A$. constricta and $P$. corium only. Total chloroplast lipids are rich in linolenic acid, which significantly decreases in the dark (Nichols, 1970). Of the five cyanobacteria studied, only Synechocystis sp. and Spirulina subsalsa contained significant amounts of linolenic acid in their total lipids, and only in the latter organism did this fatty acid decrease in the dark. However, linolenic acid in Spirulina subsalsa was not esterified in monogalactosyldiacylglycerols, as is always the case in chloroplasts, but occurred in digalactosyldiacylglycerols and sulphoquinovosyldiacylglycerols. Also $\mathrm{C}_{16: 1}$, which occurs almost exclusively in phosphatidyl glycerols in chloroplasts, is distributed among the various major classes of cyanobacteria. In none of the five cyanobacteria we studied do the individual lipid classes reveal fatty acid patterns known for comparable classes in chloroplasts, nor are the light-associated differences in the fatty acid patterns of the comparable lipid classes similar.

In conclusion, the light-associated variations in the lipids of cyanobacteria, especially in the constituent fatty acids of these lipids, are distinctly different from those known for photosynthetic eukaryotes. Another important finding is the detection of alcohol glycosides in the total lipids from three cyanobacteria. Alcohol glycosides have never been found in chloroplasts, and their presence in cyanobacteria has only been observed in heterocysts (Nichols \& Wood, 1968b; Walsby \& Nichols, 1969; Winkenbach et al., 1972). The detection of alcohol glycosides in cyanobacteria devoid of heterocysts suggests that this lipid class may be more frequent among cyanobacteria than previously assumed, and that it is not restricted to the specialized sites of aerobic nitrogen fixation.

This investigation was supported by Kuwait University, Research Council Grant no. SO 032, and KFAS Grant no. 870103 .

\section{REFERENCES}

Allen, M. M. \& Stanier, R. Y. (1968). Selective isolation of blue-green algae from water and soil. Journal of General Microbiology 51, 203-209.

Chalvardian, A. (1964). Fatty acids of brown and yellow fat in rats. Biochemical Journal 90, 518521.

Desikachary, T. V. (1959). Cyanophyta. New Delhi: Indian Council of Agricultural Research.

Dittmer, J. C. \& Lester, R. L. (1964). A simple specific spray for the detection of phospholipids on thin layer chromatograms. Journal of Lipid Research 5, 126-127.

Fogg, G. E., Stewart, W. D. P., Fay, P. \& Walsby, A. E. (1973). The Blue-Green Algae, pp. 35-77. London: Academic Press.

FolCh, J., Lee, M. \& Sloane Stanley, G. H. (1957). A simple method for the isolation and purification of total lipids from animal tissue. Journal of Biological Chemistry 226, 497-509.

GAVER, R. C. \& SweEley, C. C. (1965). Methods for methanolysis of sphingolipids and direct determina- tion of long chain bases by gas chromatography. Journal of the American Oil Chemists Society 42, 294.

Hansmann, E. (1973). Pigment analysis. In Handbook of Phycological Methods. Culture Methods and Growth Measurements, pp. 359-368. Edited by J. R. Stein. Cambridge: Cambridge University Press.

Holton, R. W., BECKER, H. H. \& ONORE, M. (1964). Effect of growth and temperature on the fatty acid composition of blue-green algae. Phytochemistry 3, $595-602$.

Holton, R. W., Becker, H. H. \& Stevens, T. S. (1968). Fatty acids in blue-green algae: possible relation to phylogenètic position. Science 160 , 545-547.

KATES, M. (1972). Techniques of Lipidology: Isolation, Analysis and Identification of Lipids, pp. 347-353. Amsterdam: North-Hölland Publishing Company.

LANG, N. J. \& WhitTon, A. B. (1973). Arrangement and structure of thylakoids. In Biology of Blue-Green Algae, pp. 66-79. Edited by N. G. Carr \& B. A. Whitton. Oxford: Blackwell Scientific Publications. 
LAUTERBORN, R. (1915). Die sapropelische Lebewelt. Verhandlungen des Naturhistorisch-Medizinischen Vereins zu Heidelberg NF13, 437-438.

LUNING, K. \& SchmitZ, K. (1988). Dark growth of the red alga Delesseira sanguinea (Ceramiales): lack of chlorophyll, photosynthetic capability and phycobilisomes. Phycologia 17, 72-77.

Mangold, H. K. \& Malins, D. C. (1960). Fractionation of fats, oils and waxes on thin layers of silicic acid. Journal of the American Oil Chemists Society 37, 383-385.

Menzies, I. S. \& Seakins, J. T. (1976). Sugars. In Chromatographic and Electrophoretic Techniques, vol. 1, p. 183. Edited by I. Smith and J. T. Seakins. London: Heinemann.

Miwa, T. K., Mikolajezak, K. L., Earle, F. R. \& WOLFF, I. A. (1960). Gas chromatographic characterization of fatty acids. Identification constants for mono- and dicarboxylic methyl esters. Analytical Chemistry 32, 1739-1742.

Nichols, B. W. (1964). Separation of plant phospholipids and glycolipids. In New Biochemical Separations, pp. 221-237. Edited by A. T. James \& L. J. Morries. London: Van Nostrand.

Nichols, B. W. (1970). Comparative lipid biochemistry of photosynthetic organs. In Phytochemical Phylogeny, pp. 105-118. Edited by J. B. Harbourne. London: Academic Press.

Nichols, B. W. \& WoOD, B. J. B. $(1968 a)$. The occurrence and biosynthesis of gamma linolenic acid in a blue-green alga, Spirulina platensis. Lipids 3, 46-50.

Nichols, B. W. \& WoOD, B. J. B. $(1968 b)$. New glycolipid specific to nitrogen-fixing blue-green algae. Nature, London 217, 767-768.

Parker, P. L., Van BaAlen, C. \& Maurer, L. (1967) Fatty acids in eleven species of blue-green algae: geochemical significance. Science 155, 707-708.

Parsons, T. R. \& Strickland, J. D. H. (1965) Particulate organic matter. III.1 Pigment analysis. III.1.1 Determination of phytoplankton pigments. Journal of the Fisheries Research Board of Canada 18, 117-127.

QuinN, P. J. \& Williams, W. P. (1983). The structural role of lipids in photosynthetic membranes. Biochimica et biophysica acta 737, 223-266.

Radwan, S. S. (1978). Coupling of two-dimensional thin layer chromatography with gas chromatography for the quantitative analysis of lipid classes and their constituent fatty acids. Journal of Chromatographic Science 16, 538-542.
RaDWAN, S. S. (1984). Glycerophospholipids. In Handbook of Chromatography. Lipids, vol. I, pp. 481508. Edited by G. Zweig, J. Sherma \& H. K. Mangold. Boca Raton, Florida: CRC Press.

RADWAN, S. S. \& MaNGOLD, H. K. (1980). Biochemistry of lipids in plant cell cultures. In Advances in Biochemical Engineering, pp. 109-133. Edited by A. Fiechler, T. K. Ghose \& N. Blakebrough. Berlin: Springer.

RipPKa, R., Deruelles, J., Waterbury, J. B., Herdman, M. \& Stanier, R. Y. (1979). Generic assignments, strain histories and properties of pure cultures of cyanobacteria. Journal of General Microbiology 111, 1-61.

Sallal, A.-K., Ghannoum, M. A., Al-Hasan, R. H., Nimer, N. A. \& RADWAN, S. S. (1987). Lanosterol and diacylglycerophosphocholines in lipids from whole cells and thylakoids of the cyanobacterium Chlorogloeopsis fritschii. Archives of Microbiology 148, $1-7$

Sato, N. \& Murata, N. (1980). Temperature shiftinduced responses in lipids in the blue-green alga Anabaena variabilis. The central role of diacylmonogalactosylglycerol in thermoadaptation. Biochimica et biophysica acta 619, 353-366.

Sato, N. \& Murata, N. (1982). Lipid biosynthesis in the blue green alga Anabaena variabilis. II. Fatty acids and lipid molecular species. Biochimica et biophysica acta 710, 279-289.

StUlP, B. K. (1982). Morphological variability of Anabaena strains under different culture conditions. Archiv für Hydrobiologie (Suppl.) 63, 165-176.

Siakotos, N. A. \& Rouser, G. (1965). Analytical separation of nonlipid water soluble substances and gangliosides from other lipids by dextran gel column chromatography. Journal of the American Oil Chemists Society 42, 913-919.

Vioque, E. (1984). Spray reagents for thin layer chromatography (TLC) and paper chromatography (PC). In Handbook of Chromatography. Lipids, vol. II, pp. 309-317. Edited by G. Zweig, J. Sherma \& H. K. Mangold. Boca Raton, Florida: CRC Press.

Walsby, A. E. \& Nichols, B. W. (1969). Lipid composition of heterocysts. Nature, London 221, 673-674.

Waterbury, J. B. \& Stanier, R. Y. (1978). Patterns of growth and development in pleurocapsalean cyanobacteria. Microbiological Reviews 42, 2-44.

Winkenbach, F., Wolk, C. P. \& Jost, M. (1972). Lipids of membranes and of cell envelope in heterocysts of a blue green alga. Planta 107, 69-80. 